address this has become vital. Adverse child behaviour, in terms of low physical activity and high sedentary time, has increased alongside rates of over-weight and obesity. However, research on these aspects of physical health is limited in young children.

Methods 275 5-year-old children from the ROLO Kids study were included in this study. Parental-reported physical activity levels were collected using the CLASS questionnaire along with information on screen time. Child anthropometry including height, weight, circumferences and skinfold thickness were collected, along with heart rate and blood pressure. T-tests, Mann-Whitney $\mathrm{U}$, and Chi-square tests were used to compare the participants and linear regression models were used to control for confounders.

Results Male 5-year olds spent more time in vigorous physical activity and in front of a screen than females $(\mathrm{P}<0.05)$. $37.5 \%$ of the cohort were not meeting the WHO physical activity guidelines of more than one hour per day and $73.4 \%$ were exceeding the AAP guidelines for screen time of less than one hour per day. After controlling for confounders, vigorous physical activity was positively associated with child weight and BMI, while screen time was positively associated with waist to height ratio $(\mathrm{P}<0.05)$. Those meeting the guidelines for screen time also had reduced waist to height ratio $(\mathrm{P}<0.05)$.

Conclusion Three quarters of the cohort exceeded recommendations for screen time, which, as these findings indicate, could have a detrimental impact on body composition. Further research is required in this area to expand on the importance of physical activity and screen time in 5-year old children.

\section{P522 THE INCIDENCE OF MACROSOMIA IS HIGHER IN A COHORT OF CHILDREN ATTENDING A WEIGHT MANAGEMENT CLINIC}

${ }^{1}$ Claire O'Hagan, 'Sophie Sharpe*, ${ }^{2}$ Sinead Murphy. 'University College Dublin, Dublin, Ireland; ${ }^{2}$ Temple Street Children's University Hospital, Dublin, Ireland

10.1136/archdischild-2019-epa.857

Introduction Childhood obesity is a rapidly growing issue worldwide today. As of 2017, in Ireland at least 1 in 5 children are overweight or obese. ${ }^{1}$ Studies have suggested that macrosomic infants are at increased risk of developing childhood obesity. ${ }^{2}$ Fetal macrosomia is defined as a birthweight $>4000$ g. ${ }^{3}$ The 2014 Irish census revealed that $15.39 \%$ of babies were born $>4000 \mathrm{~g},{ }^{4}$ however, international data has cited rates as low as $7.5 \%$.

Aim To determine whether a cohort of children attending a paediatric weight management clinic had a higher incidence of macrosomia at birth compared against the national average.

Method A retrospective cohort study design examining patients that had attended a weight management programme in Temple Street Children's University Hospital from January to December 2016 and observing the presence of macrosomia at birth. Results Out of 135 patients, 28 were recorded as having a birth weight $>4000 \mathrm{~g}(20.7 \%)$. From these 28 patients, 19 were grade 1,7 were grade 2 and 2 were grade 3.17 were male $(60.7 \%)$ and 11 were female (39.3\%).

Conclusion There is a higher incidence of macrosmia in patients with a BMI >98th percentile attending a weight management clinic than in the national average $(20.7 \%$ vs $15.39 \%)$

Discussion Our result implies association between macrosomia and childhood obesity. By expanding the cohort to include children attending a weight management programme over more than one year, this would strengthen the accuracy of our results. By selecting a cohort from one year of the programme, the sample size was limited to 230 people. Additionally, this observational study was dependent on birth weight recordings in patient charts which was subject to recall bias.

\section{REFERENCES}

1. HSE. Childhood obesity levels stabilizing but remain an issue in Ireland [Internet]. Dublin, HSE; 2017 [updated 2017 May 4th, cited 2018 February 7th]. Available from: https://www.hse.ie/eng/services/news/media/pressrel/Childhood-obesity-levels-stabilising-but-remain-an-issue-in-Ireland.html

2. Persons RK, Sevdy LT. Does birth weight predict childhood obesity? I Fam Pract [Internet] 2008:57(6):409-410 Available from: www.mdedge.com/ffponline/article/ 63185/obesity/does-birth-weight-predict-childhood-obesity

3. Walsh JM, McGowan CA, Mahony R, Foley ME, McAuliffe FM. Low glycemic index diet in pregnancy to prevent macrosomia (ROLO study): randomized contro trial. BMJ [Internet] 2012 August 1 [cited 2018 February 7]. 345(5605) Available from: http://www.bmj.com/content/345/bmj.e5605

4. CSO. Vital statistics annual Report 2014. Cork. 2014. Available from: www.cso ie/en/releasesandpublications/ep/p-vsar/vsar2014/births2014/

\section{P523 RELATIONSHIP BETWEEN TSH LEVEL AND CARDIOMETABOLIC RISK FACTORS IN OVERWEIGHT AND OBESE TURKISH ADOLESCENTS}

${ }^{1}$ Asll Okbay Güneş ${ }^{*},{ }^{2}$ Müjgan Alikaşifoğlu, ${ }^{3}$ Ethem Erginöz, ${ }^{4}$ Selmin Köse, ${ }^{1}$ Emre Çelik, ${ }^{5}$ Oya Ercan. 'Istanbul University-Cerrahpaşa, Department of Pediatrics, Istanbul, Turkey; ${ }^{2}$ Istanbul University-Cerrahpaşa, Department of Pediatrics, Division of Adolescent Medicine, Istanbul, Turkey; ${ }^{3}$ Istanbul University-Cerrahpașa, Department of Public Health, Istanbul, Turkey; ${ }^{4}$ Istanbul Bilim University, School of Health, Istanbul, Turkey; ${ }^{5}$ Istanbul University Cerrahpaşa, Department of Pediatrics, Division of Adolescent Medicine and Endocrinology, Istanbul, Turkey

\subsection{6/archdischild-2019-epa.858}

Objectives Among obese children TSH levels have been noted to be higher than normal weight children and, in some studies high TSH levels were found to be associated with cardiometabolic risk factors. The aim of this study was to investigate the relationship between TSH levels and cardiometabolic risk factors in obese and overweight adolescents.

Methods We performed a retrospective cross-sectional analysis of the data from 343 overweight or obese adolescents 11-18 years of age who were evaluated in our clinic from January 2012 to December 2015. Hypertension, dyslipidemia, hyperinsulinemia, hyperglycaemia and insulin resistance were defined as cardiometabolic risk factors. Patients' TSH and free T4 levels were recorded and only those subjects whose free T4 was normal were included in the study. For statistical analysis, Spearman correlation test and linear logistic regression analysis were used.

Results Among 343 adolescents; 25.1\% were overweight, and $74.9 \%$ were obese. In the study group, the mean age was $14.03 \pm 1.76$ years and $59.8 \%$ of the subjects were girls. The SDS-BMI was in median $2.4 \pm 0.64$. A significant positive correlation was found between TSH level and HOMA-IR, insulin and triglyceride levels $(\mathrm{P}=0.001,0.001,0.006$, respectively). In the linear regression analysis in which age, gender and BMI-SDS values were taken as co-variates, a $10 \%$ increase in the geometric mean of TSH was associated with 0.13 fold 